\title{
Innovative bolted end-plate connections for high web I-beams
}

\author{
P. Tucki \& E. Hotała \\ Department of Civil Engineering, Wroctaw University of Science and Technology, Wroctaw, Poland
}

\begin{abstract}
Solid end-plate connections are commonly used in bolted joint of solid I-beam elements. But effective use is made only of the plate fragments lying adjacent to the webs and flanges of the I-beams. The paper presents the potential of using innovative bolted end-plate connections comprising independent T-stubs instead of traditional solid end-plates in relation to the example of steel I-beams with high webs. It has been shown that such innovative end-plate connections are justified economically, can be easily manufactured, and provide comparable load-bearing capacity and stiffness to traditional solid end-plate connections. The influence of T-stubs plate thickness on the load-bearing capacity and stiffness of these innovative connections has been demonstrated. Attention is drawn also to easier compliance with flatness standards of the independent T-stubs plates when compared to large solid end-plates.
\end{abstract}

\section{INTRODUCTION}

Bolted end-plate connections of I-beams with high webs requiring many rows of bolts pose considerable problems to designers and contractors. The calculation methods contained in (EN 1993-1-8) are insufficient for determining the load-bearing capacity of such connections, as the calculated standard load-bearing capacity is significantly overestimated, as has been demonstrated in several publications (Kawecki et al. 2016, Żółtowski et al. 2016). An acceptable differential in load-bearing capacity standards obtained from the calculations and from FEM analysis can be achieved by determining load-bearing capacity on the basis of a consideration of only two rows of bolts located directly adjacent to the tension zone and in the zone of the next row away from the tension zone, if there is one. Large end-plates in the connections are subject to large deformation during welding, which means that it is difficult to meet the flatness requirement of the EN-1090-2 standard.

Paper (Hotała et al. 2020) present end-plate connections as an innovative solution as they are not focused on a single end-plate on the front edge of the I-beam element, but on several independent small end-plates with the bolt holes, which are referred to as independent T-stubs. These T-stubs are not connected to one another. The small plates are welded onto the flanges, whereas others are welded on the I-beam web, which means that they constitute independent $\mathrm{T}$-stubs. The individual end-plates in these independent $\mathrm{T}$-stubs include bolt-holes and are welded onto the flanges of the I-beam or its web, with the proviso that each one of these end-plates is welded onto only one of the two flanges of the I-beam or to the web of the I-beam or else to one of the flanges and web. In this study, the results of a numerical analysis of T-stubs end-plate connection of an HEB400 beam are presented, showing that this kind of innovative connection can achieve comparable load-bearing capacity and stiffness to that of a single solid end-plate connection. Elimination of the cross T-stubs (consisting of solid endplates connected to flange and web) should ensure a high capability for rotating the joint, 
while bringing into play the bolts adjacent to web. In the paper was shown next analysis phase of an end-plate connection with T-stubs.

The authors of this paper are convinced that with a moment end-plate connection, the rows of bolts located away from the tension flange, adjacent to the web can contribute effectively to increasing the load-bearing capacity of the end-plate connection if that connection has a high rotational capability, as only then high tensile forces can occur in these bolt rows.

Designing moment end-plate connection of high beams with solid end-plates leads the problem of ensuring a sufficient rotational capability, while ensuring at the same time high loadbearing capacity of the connection. A problem arises from the limited capability of the bolts under tension to elongate, especially those which are high strength. When using thick endplates, the rotational capability depends on the ability of the bolts under tension to elongate. The rotational capability of the connection can be very beneficial for the design of systems, which require flexible joints, which provide for a planned distribution of bending moments.

This paper presents the results of comparative analysis of a traditional end-plate connection with solid end-plates and an innovative end-plate connection comprised of independent T-stubs used in a beam with high web $h_{w}=900 \mathrm{~mm}$. The influence of connection flexibility was analysed on the distribution of bending moments in the middle of the bending beam span.

\section{FEM ANALYSIS}

The end-plate connections of the I-beam shown in (Figure 1) provided the focus for a comparative numerical analysis. Connections with solid end-plates and independent T-stubs of a thickness of $\mathrm{t}=20,24,28 \mathrm{~mm}$ (solid and independent T-stubs) were analysed comparatively. The bolt arrangement in each case was identical. A numerical FEM model of the I-beams analysed was constructed, based on a simple-supported beam static schema of a $2 \mathrm{~m}$ span, and with boundary conditions imposed on the lower edge of the beam profile. A bending moment was applied using the pressure at the ends of the profiles. In all models longitudinal symmetry was used, which was ensured through using appropriate boundary conditions.

The modelling method for contact and the finite elements used are the same as those in (Hotała et al. 2020). The elastic-plastic model for S355 steel was used. Class 10.9 bolt material was also modelled as ideally elastic-plastic as $f_{u b}=720 \mathrm{MPa}, a f_{y b}=900 \mathrm{MPa}$. The boundary limit for deformation of bolt material under tension was adopted in accordance with EN ISO $898-1: 2013$ ), i.e. $\varepsilon_{\lim }=9 \%$. The load-bearing capacity of the I-beam profile analysed was $\mathrm{M}_{\mathrm{c}, \mathrm{Rd}}=2750 \mathrm{kNm}$. The authors are familiar with the models of materials used for FEM calculations of bolted connections, e.g. (Sumner 2003), but these were not used as the calculation parameters for the materials as these were taken from the EN 1993-1-8 standard.

As a result of the numerical analyses, determination was made of the static equilibrium paths and force distribution of the connections analysed at the ultimate limit state of their load-bearing for different thicknesses of end-plates. The static equilibrium paths are presented in (Figure 2).

The distribution of forces $F_{t}$ in bolts and the distribution of effective forces $F_{t, \text { eff }}$ in bolts are presented in (Figure 3), but only for plate thicknesses $t=28 \mathrm{~mm}$. The lower flanges of the beam are tensioned at the joint. In each case, the new connection type made with independent T-stubs had a rotation capability of $22 \%$ to $42 \%$ higher than in the solid plate connection. The greatest increase in rotational capability combined with only a small loss in load-bearing capacity was achieved for a $28 \mathrm{~mm}$ thick connection when compared to the solid end-plate. The values of bolt forces in both types of connection (solid end-plate, independent T-stubs) are presented in (Figure 3). The indication is that in connection with independent T-stubs, there are slightly higher effective forces in the bolts in the rows above the tension flange at the beam web than in the case of the solid plate. The exception is bolt $3 \mathrm{~A}$ in connection with solid endplate, as in this case the prying forces are concentrated on the level of bolt $4 \mathrm{~A}$, which means that the effective force in bolt $3 \mathrm{~A}$ cannot be unambiguously determined. The distribution of the prying effect of reactive forces is shown in (Figure 4). It should be noted that in both 


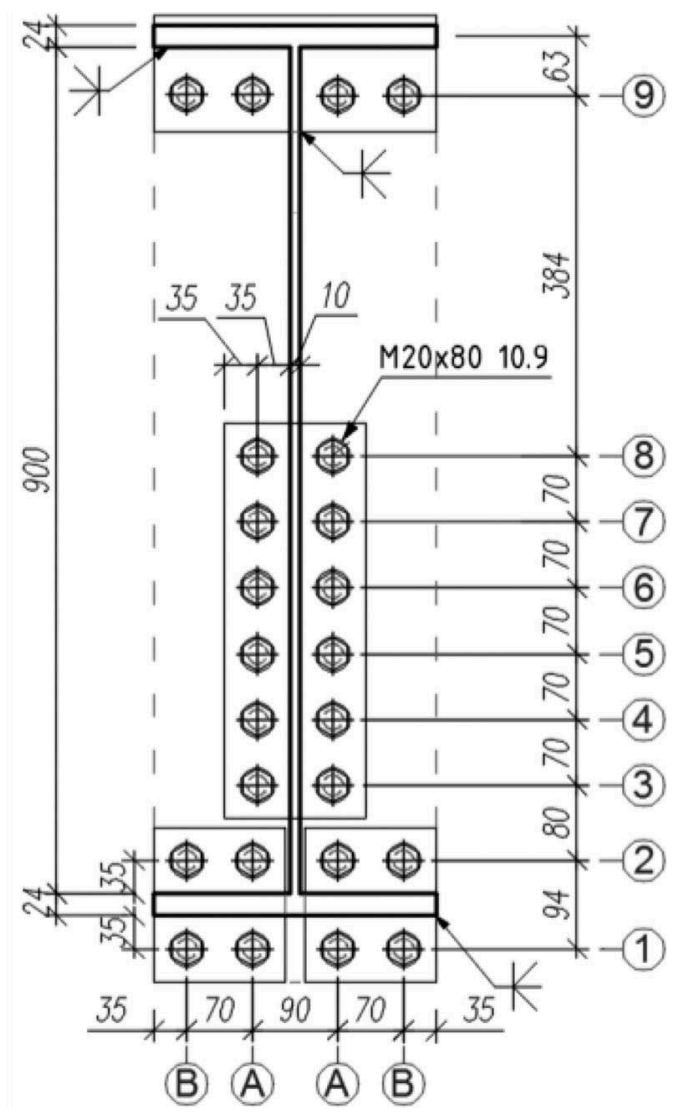

Figure 1. Geometry of the connection analysed with independent T-stubs and with a solid end-plate. The contour of the solid plate is indicated with a dashed line. Bolt row numbers: $1-9$.

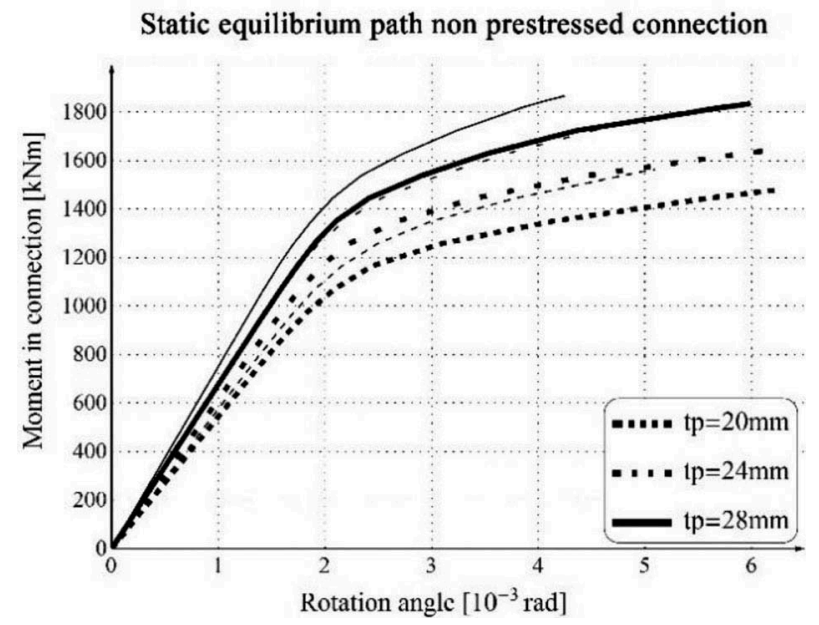

Figure 2. Static equilibrium paths for non prestressed connections. The thick lines mark the paths of connections with independent T-stubs. The thin lines indicate the paths of connections with a solid end-plate. 


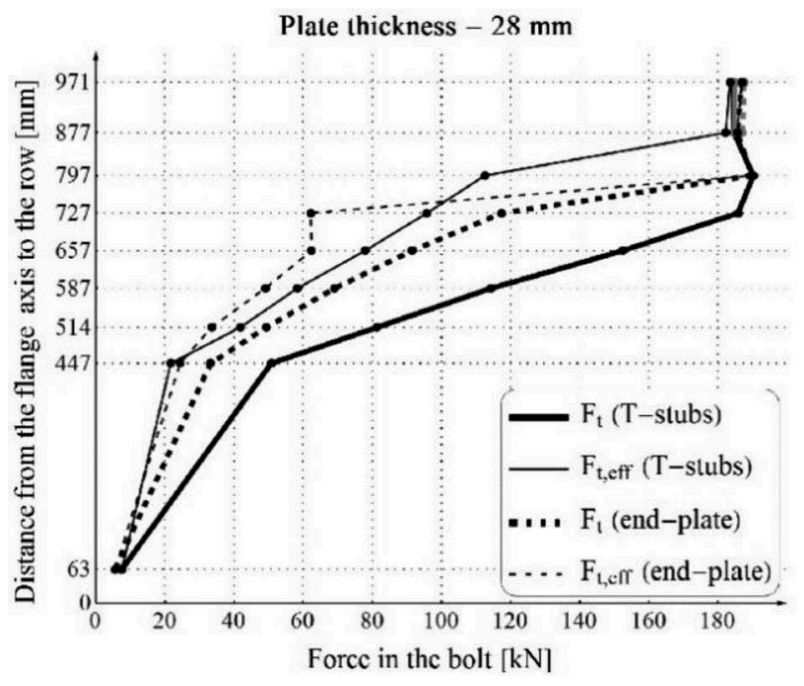

Figure 3. Values of bolt forces in combination with end plate $t=28 \mathrm{~mm}$. The bolts in vertical row A presented in (Figure 1), are marked in black and bolts in the vertical row B are marked in grey. Continuous lines refer to the independent $\mathrm{T}$-stubs and dashed lines are for the solid end-plates.

a)

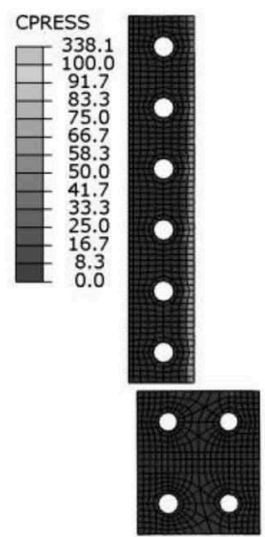

b)

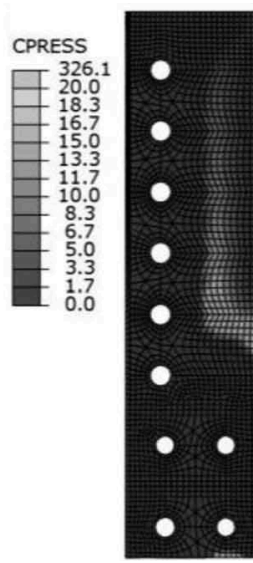

Figure 4. Distribution of pressure stress (light colouring) on end-plates resulting from the prying effect for: a) independent $\mathrm{T}$-stubs, b) solid end-plates.

models the effective forces in bolts (Figure 3) in the row 1 and 2 are to high. It can be result from the coarse mesh hence bolts fail according to model 3 in (EN 1993-1-8). Despite that connections with T-stubs have better rotational capacity. An analysis with thicker mesh should be performed. 


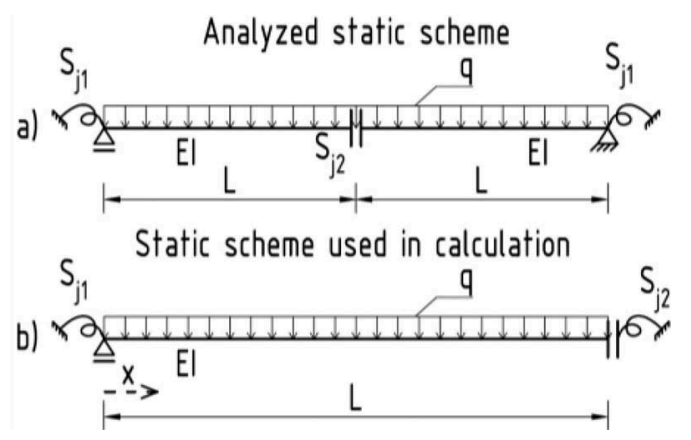

Figure 5. Symbols explanation used in in equation (3) and (Tabs 1,2).

\section{ANALYSIS OF A FLEXIBLY CONNECTED CONTINUOUS BEAM}

When designing bending beams with flexible support, the aim is to ensure bending moments above the supports and in the beam span are of comparable value. If a flexible joint is applied at the end of a beam, the desired bending moment distribution can be achieved.

Based on the graphs presented in (Figure 2), it can be concluded that the innovative type of connection made with independent $\mathrm{T}$-stubs can achieve a substantially greater rotational capability than the traditional type of connection with a solid end-plate, and is therefore much better suited to the type of situation described above. It was decided to investigate the influence of better rotational capability of a high end-plate connection on the ultimate load capacity of a $2 \mathrm{~L}$ span I-beam, taking into account the node flexibility (Figure 5a). The static scheme, which was taken into account in the calculations was shown in (Figure 5b). Using symmetry, scheme $5 \mathrm{a}$ can be transformed into scheme $5 \mathrm{~b}$. Thanks to this procedure, it is possible to take into account the connection flexibility in the middle of the beam span without dividing the beam into two for calculation purposes.

Applying the differential equation of the beam deflection line (1), formulas were introduced for deriving all variable values in relation to boundary conditions assumed (2). Solving the equation (1) provided the following function (3).

$$
\begin{gathered}
\frac{d^{2}}{d x^{2}}\left(E I \frac{d^{2} u(x)}{d x^{2}}\right)=-q(x) \\
u(0)=0, u^{\prime}(0)=u^{\prime \prime}(0) \cdot E I / S_{j 1}, u^{\prime}(L)=-u^{\prime \prime}(L) \cdot E I / S_{j 2}, u^{\prime \prime \prime}(L)=0 \\
M\left(x, L, E I, q, S_{j 1}, S_{j 2}\right)=\frac{1}{6 E I} \cdot q\left(-\frac{L^{2} S_{j 1}\left(3 E I+2 L S_{j 2}\right)}{L S_{j 1} S_{j 2}+E I\left(S_{j 1}+S_{j 2}\right)}+6 L x-3 x^{2}\right)
\end{gathered}
$$

In (Tab. 1) the results of the calculation are provided for a beam with a length of $2 \mathrm{~L}=$ $20 \mathrm{~m}$ flexibly connected on both sides ( $\mathrm{L}=10 \mathrm{~m}$ had to be entered into equation (3)). The secant stiffness $S_{j, \text { sec }}$ of the connection was applied, and (Tab. 1) presents the relative stiffness of the connection in relation to the stiffness of the cross-section. The designation $\mathrm{q} \Delta \mathrm{M}$ indicates the value of the load to be applied to the beam to bring about in the support a moment of value $M_{\text {max.. }}$ The results of the calculation analyses carried out are presented in (Tab. 2). These are equivalent to those presented in (Tab. 1), with the difference that in the middle of the beam of $2 \mathrm{~L}=20 \mathrm{~m}$ span (Figure $5 \mathrm{a}$ ) the connection was the same as that of the support. It was sufficient to use the initial stiffness of the connection at the middle of the beam span in both cases, as the span moments attained a value close to that, at which the joint starts to become plastic. 
Table 1. Flexibility connections in the ends of the beam, $\mathrm{t}_{\mathrm{p}}=28 \mathrm{~mm}\left(\mathrm{~S}_{\mathrm{j}, \mathrm{sec}}=\mathrm{M}_{\mathrm{j}, \mathrm{Rd}} / \Phi_{\mathrm{Cd}}\right)$.

\begin{tabular}{lllllllll}
\hline $\begin{array}{l}\text { Type } \\
{[-]}\end{array}$ & $\begin{array}{l}\mathrm{EI} \\
\mathrm{MNm}^{2}\end{array}$ & $\begin{array}{l}\mathrm{S}_{\mathrm{j}, \text { ini }} / \mathrm{EI} \\
1 /(\mathrm{m} \cdot \mathrm{rad})\end{array}$ & $\begin{array}{l}\mathrm{M}_{\mathrm{j}, \mathrm{Rd}} \\
\mathrm{kNm}\end{array}$ & $\begin{array}{l}\Phi_{\mathrm{Cd}} \\
10^{-3} \mathrm{rad}\end{array}$ & $\begin{array}{l}\mathrm{S}_{\mathrm{j}, \text { sed }} / \mathrm{EI} \\
1 /(\mathrm{m} \cdot \mathrm{rad})\end{array}$ & $\begin{array}{l}\mathrm{q} \Delta \mathrm{M} \\
\mathrm{kN} / \mathrm{m}\end{array}$ & $\begin{array}{l}\mathrm{M}_{\text {support }} \\
\mathrm{kNm}\end{array}$ & $\begin{array}{l}\mathrm{M}_{\text {span }} \\
\mathrm{kNm}\end{array}$ \\
\hline New & 773 & 0.86 & 1838 & 5.98 & 0.39 & 68.4 & 1838 & 1590 \\
Old & 773 & 0.94 & 1861 & 4.22 & 0.54 & 65.2 & 1861 & 1404 \\
\hline
\end{tabular}

Table 2. Flexibility connections in the ends and in the middle of the beam, $t_{\mathrm{p}}=28 \mathrm{~mm}\left(\mathrm{~S}_{\mathrm{j}, \mathrm{sec}}=\mathrm{M}_{\mathrm{j}, \mathrm{Rd}} / \Phi_{\mathrm{Cd}}\right)$

\begin{tabular}{lllllllll}
\hline $\begin{array}{l}\text { Type } \\
{[-]}\end{array}$ & $\mathrm{EI}_{\mathrm{HNm}}{ }^{2}$ & $\begin{array}{l}\mathrm{S}_{\mathrm{j}, \text { ini }} / \mathrm{EI} \\
1 /(\mathrm{m} \cdot \mathrm{rad})\end{array}$ & $\begin{array}{l}\mathrm{M}_{\mathrm{j}, \mathrm{Rd}} \\
\mathrm{kNm}\end{array}$ & $\begin{array}{l}\Phi_{\mathrm{Cd}} \\
10^{-3} \mathrm{rad}\end{array}$ & $\begin{array}{l}\mathrm{S}_{\mathrm{j}, \text { sec }} / \mathrm{EI} \\
1 /(\mathrm{m} \cdot \mathrm{rad})\end{array}$ & $\begin{array}{l}\mathrm{q} \Delta \mathrm{M} \\
\mathrm{kN} / \mathrm{m}\end{array}$ & $\begin{array}{l}\mathrm{M}_{\text {support }} \\
\mathrm{kNm}\end{array}$ & $\begin{array}{l}\mathrm{M}_{\text {span }} \\
\mathrm{kNm}\end{array}$ \\
\hline New & 773 & 0.86 & 1838 & 5.98 & 0.39 & 64.3 & 1838 & 1365 \\
Old & 773 & 0.94 & 1861 & 4.22 & 0.54 & 61.7 & 1861 & 1220 \\
\hline
\end{tabular}

The results of the analyses presented in (Tabs 1,2) indicate that for a beam that has a very rigid connection in the middle of its span or is continuous, the ultimate loading capacity is $4.9 \%(68.4 / 65.2=1.049)$ higher for the innovative connection as compared to the solid end-plate connection. If there is a joint in the middle of the span of the same characteristics as that of the support, the load-bearing capacity is $4.2 \%(64.3 / 61.7=1.042)$ higher for the innovative connection At the same time, taking into account the flexibility of the connection in the middle of the span reduces the ultimate load-bearing capacity by about $5 \%$ in both connection types.

\section{DISCUSSION}

When making a non-prestressed connection according to the EN 1090-2 standard, a separation up to $4 \mathrm{~mm}$ is allowed on the end-plate edges. The value of stiffness coefficients of the basic parts of the connection in line with the EN 1993-1-8 standard were introduced as a perfectly flat surface of the end-plate. As a thought experiment, consideration was given to a tensile connection which fails according to model no. 2 of this standard. Analysing behavior of a tensile connection with edge imperfections, indicates that, first of all, the end-plate starts to work as a cantilever and at a certain point it starts to become plastic, significantly impacting the stiffness of the connection. Only as a result of further plasticization will the end-plates come into contact with one another, and at this point the connection will have reached its ultimate loading capacity.

It is worth noting that the more flexible the connection in the middle of the beam span, the lower the load-bearing capacity of the whole system. (Basiński 2006) examined similar connections $\left(\mathrm{h}_{\mathrm{w}}=500 \mathrm{~mm}, \mathrm{t}_{\mathrm{p}}=30 \mathrm{~mm}, \mathrm{~d}=20 \mathrm{~mm}\right)$, and found that a four-fold difference in connection initial stiffness resulted from random prying effects.

Due to random prying effects appearing, an analysis was carried out to determine how much the support moment increases, if the connection stiffness in the middle of the beam span has decreased in an unpredictable way, e.g. due to imperfections introduced during construction and random prying effects. Based on (Tabs 1,2), the support stiffness is taken to be the secant stiffness of the connection, which is about 0.5 times the initial stiffness. In the denominator of expression $\mathrm{k}$ (Figure 6), the connection stiffness in the middle of the beam span is the same as the initial stiffness, because the moment in the beam span is not large and a connection of ideal geometry in most cases will not yet be turning plastic. Variable parameters were values of the connection initial stiffness in the middle of the beam span $S_{j 2 \text {,ini }}$ and value $\mathrm{x}$, which indicates what part of the stiffness remains in the connection as a result of 


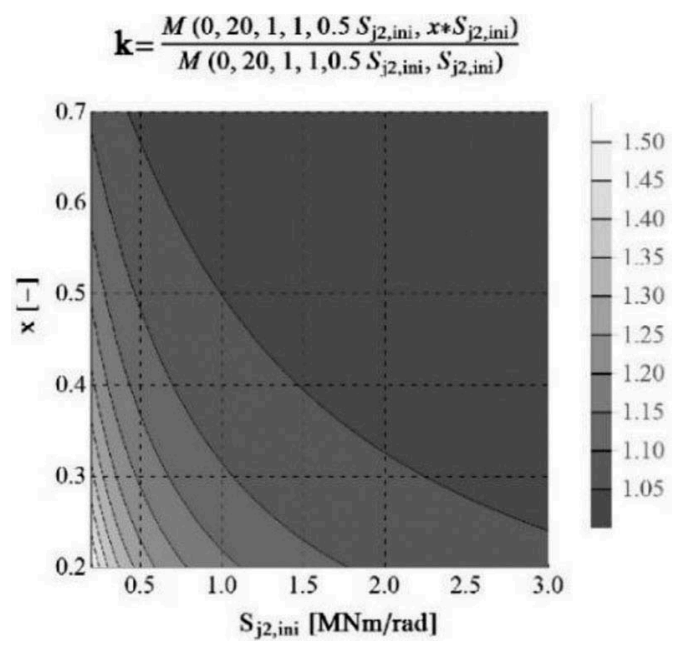

Figure 6. Increase of the beam support moment (Figure 5) as a result of a decrease of the joint stiffness in the middle of the beam span, caused by random effects of separation of end-plates.

random separation of the end-plates and their earlier plasticization, which due to separation acts as a cantilever in the initial work phase of the connection.

Based on the graphs presented in (Figure 6), it can be concluded that for beams with flexible connections, which have the same type of connection in the middle of their span as in the support, the decrease in stiffness is significant for the ultimate load bearing capacity of the whole beam.

\section{CONCLUSIONS}

In spite of up to $42 \%$ greater rotational capability (Figure 2 ) of the innovative type of connection using independent T-stubs as compared to connections with solid end-plates, it has not proven possible to make effective use of a much larger number of bolts arranged in tension series that are located adjacent to the web (Figure 3). Although the load-bearing capacity of the innovative connection is slightly lower than that of an equivalent connection comprising a solid end-plate, the analysis indicates that for certain thickness of end-plates, the ultimate load-bearing capacity of the beams with flexible end-plates (Figure 6) will be higher than for a traditional type of connection.

Given that bolted connections are not always compressed, it makes sense to determine the static equilibrium paths of imperfections of high connections, and then to check on the impact on ultimate load-bearing capacity of beams with flexible end connections in the middle of the beam span. This is an important issue as high web beam connections can be designed for high load-bearing capacity, even $\mathrm{M}_{\mathrm{j}, \mathrm{Rd}}=0.7 \mathrm{M}_{\mathrm{c}, \mathrm{Rd}}$, and for relatively low stiffness.

Only preliminary results were shown and an experimental verification is needed.

Calculations were carried thanks to resources provided by the Wroclaw Centre for Networking and Supercomputing (http://wcss.pl) under grant No. 81.

\section{REFERENCES}

Basiński W. 2006. Determination flexible end-plate connections rotational stiffness in metal structures on the basis of vibrations, Doctoral dissertation, Silesian University of Technology. (in polish)

EN 1090-2 - Execution of steel structures and aluminium structures - Part 2: Technical requirements for steel structures. 
EN 1993-1-8 Eurocode 3 - Design of Steel Structures Part 1-8 Design of Joints.

Hotała E. \& Tucki P. 2020. Innovative bolted end-plate connections for steel I-beams, Builder; 273 (4): 100-103. DOI: $10.5604 / 01.3001 .0013 .8798$

ISO 898-1:2013 - Mechanical properties of fasteners made of carbon steel and alloy steel - Part 1: Bolts, screws and studs with specified property classes - Coarse thread and fine pitch thread.

P. Kawecki \& J. Łaguna \& A. Kozłowski. 2016. FEM analysis of the extended end-plate splice of welded I-girders with multiple bolt rows and bolts per row, Proceedings of the XIII International Conference on Metal Structures (ICMS2016), Zielona Góra, Poland, 15-17 June 2016, Taylor \& Francis Group.

Sumner E. 2003. Unified Design of Extended End-Plate Moment Connections Subject to Cyclic loading. Dissertation submitted to the Faculty of the Virginia Polytechnic Institute.

Żółtowski K. \& Kalitowski P. 2016. Moment resistance of I-section end-plate roof girder splices; a case study, Archives of Civil Engineering, Vol. LXII, ISSUE 4, Part 1, s.187-200. 